\title{
PENSANDO OS FENÔMENOS PSICOLÓGICOS: UM ENSAIO ESQUIZOANALÍTICO
}

\author{
Roberta Stubs Parpinelli* \\ Edmilson Wantuil Freitas de Souza"
}

\begin{abstract}
RESUMO. $O$ artigo se apropria de algumas idéias e conceitos da teoria esquizoanalítica e os utiliza para repensar os fenômenos psicológicos e a própria realidade. A idéia de devir, a concepção de subjetividade, de inconsciente, de desejo, de rizoma, de agenciamento, de multiplicidade, de vozes de poder, de saber e de auto-referência, etc. são alguns elementos tomados de empréstimo da esquizoanálise para conferir um entendimento renovado aos denominados fenômenos psicológicos. A partir da discussão inspirada pelo aporte teórico das multiplicidades buscaram-se novas possibilidades para conceber tais fenômenos e a própria realidade, de modo que as dimensões éticas e políticas se façam indissociáveis do compromisso de emancipar e enriquecer a vida humana.
\end{abstract}

Palavras-chave: fenômenos psicológicos, esquizoanálise, realidade.

\section{PSYCHOLOGICAL PHENOMENA: A SCHIZOANALITIC ESSAY}

\begin{abstract}
The article makes use of some ideas and concepts from the schizoanalitic theory to rethink psychological phenomena and the reality itself. Concepts related to becoming, subjectivity, unconsciousness, desire, ryzoma, agency, multiplicity, power voices, knowledge and self-reference are some of the elements taken from schizoanalysis to renew the understanding of psychological phenomena. The multiplicity theory contributed to a discussion which started the search for new possibilities to understand such phenomena and the reality itself, where the ethical and political dimensions shall never be apart from the commitment to emancipate and enrich the human life.
\end{abstract}

Key words: psychological phenomena; schizoanalysis; reality.

O presente texto se configura como um ensaio que visa colocar em cena alguns conceitos da esquizoanálise para, então, indicar algumas possibilidades de "olhar", entender e lidar com o que se costuma designar de "fenômenos psicológicos". Desse modo, ao invés de ambicionar interpretar e traduzir o aporte esquizoanalítico, emoldurando-o num quadro explicativo, optou-se por uma reflexão inspirada em alguns conceitos e noções da teoria que conferem a esta uma concepção rizomática e dinâmica da realidade (nesta incluídas as vivências humanas), tais como a idéia de devir, a concepção de subjetividade, de inconsciente, de desejo etc.

Neste sentido, o texto se estrutura realizando, primeiramente, uma sucinta reflexão sobre os conceitos que serão utilizados na elaboração do artigo. E aqui, um cuidado necessário: o esforço para abarcar um conjunto importante de conceitos esquizoanalíticos implicou um tratamento breve de tais conceitos. A razão disso se compreenderá adiante: o texto busca, sobretudo, traçar alguns paralelos entre as idéias dos autores estudados e questões muito concretas que emergem no "campo psi”, sugerindo outros modos de entendimento. Os exemplos reunidos para esse exercício constituem muito mais um convite para ser extrapolado, modificado e até substituído por outros exemplos de que o leitor dispuser.

Como já se percebe, o percurso do artigo segue, após as reflexões teóricas acerca dos conceitos elencados, para a interpretação de alguns fenômenos do campo "psi", seja nas vivências humanas seja no espaço singular da clínica psicológica. $\mathrm{Na}$ análise dos exemplos apresentados, um cuidado está sempre balizando as reflexões: distinguir, por um lado, os dispositivos de controle, os arranjos coercitivos,

\footnotetext{
* Psicóloga. Discente do Curso de Especialização em Saúde Mental e Intervenção Psicológica da Universidade Estadual de Maringá.

\# Psicólogo. Mestre em Fundamentos da Educação. Docente do Departamento de Psicologia da Universidade Estadual de Maringá.
} 
paralisantes dos fluxos desejantes da vida, e por outro, os esforços de abertura para o novo, para a criação, para a invenção, enfim, para um desejo produtivo e uma produção desejante.

Neste sentido, o que se oferecerá mais adiante, na forma aberta de "conclusão", é um convite para que esse ensaio seja apropriado e transformado por outras visões e audições comprometidas com uma concepção de desejo positivo, produtivo e criador.

\section{SUBJETIVIDADE E ESQUIZOANÁLISE}

Antes de iniciar qualquer discussão acerca da subjetividade, é necessário esclarecer que esta é concebida pela esquizoanálise como um sistema aberto, constituído de múltiplas e diferentes forças, denominadas por Guattari (1993), como Equipamentos coletivos de subjetivação ou componentes de subjetivação, conceito que pode ser entendido como um agregado de inúmeras máquinas $^{l}$ que compõem a realidade. Sendo assim, subjetividade é uma noção complexa, cujo entendimento depende da articulação de aspectos psíquicos com toda a miríade de forças dinâmicas que compõem a própria realidade. Ao invés de pensar um sujeito de contornos limitados e fechado em si, a partir do qual a subjetividade brota, melhor seria pensar no cruzamento de múltiplos componentes de subjetivação que se ligam e religam e acabam influenciando a constituição da subjetividade. Para a esquizoanálise, a articulação de aspectos psíquicos com os equipamentos coletivos de subjetivação ocorre de maneira rizomática.

O rizoma é um conceito que entende a realidade e dentro dela a própria subjetividade - como uma rede constituída de inúmeras ramificações que se conectam e reconectam continuamente com outras ramificações. Segundo Lobo (2004), o rizoma procede sempre por alianças, sempre por conexões realizadas pela conjunção de elementos destituídos de pontos de chegada ou de partida, mas embebidos pelo princípio de heterogeneidade e de multiplicidade. Dessa forma, o conceito de rizoma possibilita um entendimento da

\footnotetext{
Guattari (2003) se propõe a repensar o conceito de máquina concebendo-a de maneira diferente da visão mecanicista. Para ele, a realidade é constituída "por minúsculas máquinas que se formam por si mesmas ao mesmo tempo em que funcionam" (Baremblitt, 1998b, p. 92). Dessa forma, existe na máquina alguma coisa, não de natureza humana ou animal, nem mesmo de ordem da alma, mas uma proto-subjetividade consistente.
}

(auto)constituição da subjetividade irrestrita a um número determinado de elementos. Ou seja, os elementos são múltiplos e mutáveis, eles se "plugam" a outros elementos constantemente, estando eles próprios em constante metamorfose. A partir desses elementos, a subjetividade se funda, põe-se de pé e se faz funcionar. Desse modo ela se configura num devir: é continuamente constituída a partir das ligações e religações que suas ramificações fazem e refazem com elementos intra e extrapsíquicos, individuais e préindividuais, humanos e não-humanos, orgânicos e inorgânicos...

Sendo assim, o termo extrapsíquico diz respeito a elementos da realidade. Assim como a subjetividade, a realidade também é constituída de maneira rizomática, ela se configura no entrelace de devires, imagens, objetos, afetos, etc. É no encontro de múltiplos elementos que se desenha uma cena da realidade. Uma sala de jantar se constitui de cadeiras, mesa, vasos, quadros, tapetes, arranjos florais, retratos, sujeira, poeira, pessoas, objetos, moléculas, etc. Enfim, natureza, cultura, história, tecnologia, arquitetura, ciência, são efetuações dessas ligações rizomáticas que se exprimem a partir da interpenetração de diferentes elementos. Veja-se bem, cada um desses elementos que carregam consigo um emaranhado de fatos que os antecedem constitui outra e nova malha de relações. Citem-se como exemplos o suor do artesão que talhou a mesa e as cadeiras, a genialidade de quem as projetou, as marcas naturais que o tempo se incumbiu de deixar nesses objetos, etc., mas também a dureza da madeira, a aspereza de suas fibras, a mutabilidade de suas formas, enfim, as inúmeras conexões possíveis com sua organicidade. Os retratos, por sua vez, carregam a história do fotógrafo que definiu o melhor enquadre de uma paisagem, e das pessoas cujo momento existencial foi eternizado num registro fotográfico, mas também os recursos do equipamento técnico que é utilizado, a sensibilidade da película fotográfica à luz, a própria luz, a potência inorgânica que se entrelaça com a própria vida, enfim, tudo isso agenciando e produzindo um acontecimento vivo que se exprime enquanto duração no aqui-e-agora.

Todos esses elementos precedem o objeto tal como ele se apresenta na realidade e acabam influenciando, de alguma maneira, a composição da sala de jantar. Dessa forma, toda realidade é constituída pelo encontro de elementos que se ligam e formam uma malha que pulsa informações, histórias, 
afetos, emoções, subjetividades. Para a esquizoanálise, todos esses elementos da realidade não só se relacionam com a subjetividade, mas são eles próprios possuidores de uma proto-subjetividade.

Segundo Guattari (2000, p. 161), a realidade (objetos, signos, rituais, conceitos, discursos, figuras, imagens, arquitetura, etc.) possui uma proto-subjetividade ou uma subjetividade parcial: "a cidade, a rua, o prédio, a porta, o corredor... modelizam, cada um por sua parte e em composições globais, focos de subjetivação". Dostoievski (1988, p. 7) descreve brilhantemente um momento no qual focos de subjetivação de uma rua se conectam com a subjetividade do protagonista, fazendo emergir sentimentos, emoções e afetos.

Para mim, também as casas são velhas amigas. Quando passeio, cada uma delas parece correr ao meu encontro na rua: olhame com todas as suas janelas, dizendo-me algo como isto: « Bom dia! Como estás? Eu vou bem, graças a Deus, muito obrigada! Em Maio vão-me aumentar um andar. $>>\mathrm{Ou}:<<$ Como vais? Amanhã vou entrar em obras. $>$

Retomando o exemplo da sala de jantar, a protosubjetividade agenciada neste espaço físico transborda sinais que, ao se conectarem com a subjetividade das pessoas que transitam por ela, podem despertar diferentes sentimentos e sensações, que crispam na constituição mesma desse espaço físico. Caso uma pessoa que se encontre presa num enredo obsessivo entre nessa sala e esta esteja "extremamente bagunçada" (ou seja, em desacordo com o conceito dominante de ordem), a proto-subjetividade da sala atuaria como um componente de subjetivação que se conectaria com os núcleos obsessivos enrijecidos da pessoa, que passaria então a arrumar a sala, obedecendo aos comandos de um superego que, como se vê, não é apenas uma instância interna, mas um dispositivo servomecânico que se rearticula sempre com a dimensão espacial no aqui-e-agora. Seria agenciada nesse processo de arrumação uma velha subjetividade tanto a nível intrapsíquico - a pessoa em questão repetiria uma confinada satisfação, já que poria como sempre a sala em ordem - quanto ao nível extrapsíquico - a sala ganharia a composição dominante da ordem que se repete como um modelo de realidade.

\section{CARACTERÍSTICAS DO RIZOMA}

Deleuze e Guattari (1996) enumeraram algumas características do rizoma. A primeira diz respeito ao princípio de conexão e de heterogeneidade a partir do qual se entende que qualquer parte do rizoma pode se conectar com qualquer parte de outro rizoma, possibilitando uma contínua ligação e religação com outros elementos. A conexão é uma forma de entender um fenômeno através de um descentramento sobre outras dimensões e registros.

Sob certa leitura psicanalítica, que aqui simplificaremos bastante, no paranóico, por exemplo, ou melhor, num indivíduo em vivência paranóide seus delírios de perseguição seriam sobretudo reações defensivas que visam projetar a hostilidade, advinda de uma fixação na fase sádico-expulsiva da fase anal, no meio externo. Tais fixações estariam especialmente relacionadas com suas primeiras vivências psíquicas no âmbito familiar, principalmente em relação aos genitores, primeiros objetos de amor.

A concepção esquizoanalítica amplia este entendimento da paranóia articulando-o com uma das duas possibilidades de investimento desejante das vivências humanas, que podem, de um lado, banhar-se nos fluxos esquizos do inconsciente e verter como criação, devir, singularidade; ou então, engastar num outro extremo dessa experiência desterritorializante sentida como sufocamento e morte, petrificando-se, atando-se ao enredo repetitivo do delírio paranóico frente ao fascínio das intensidades puras. Em verdade, dizem Deleuze e Guattari (1976), as intensidades puras se constituem a partir de duas forças contrastantes que fazem frente ao nível de intensidade zero do corpo sem órgãos.

De onde vêm essas intensidades puras? Vem das duas forças precedentes de repulsão e atração, e da oposição dessas duas forças. Não que as intensidades estejam em oposição umas com as outras e se equilibrem em volta de um estado neutro. Ao contrário, elas são todas positivas a partir da intensidade $=0$ que designam o corpo pleno sem órgãos (Deleuze \& Guattari, 1976, p. 22).

Segundo os autores, o corpo pleno sem órgão é um conceito complexo que busca levar o pensamento até o improdutivo, o inengendrável, o amorfo, o indiferenciado, que podem funcionar como antiprodução, mas com o qual as máquinas desejantes podem se acoplar, produzindo os "devires, as passagens, as destinações daquele que aí se desenvolve" (Deleuze \& Guattari, 1976, p. 35). A paranóia corresponderia, assim, a um dos pólos possíveis de investimentos frente à atração miraculante da antiprodução do corpo sem órgãos. Como tal, ela se expressaria na forma de "engessamento", repetição do mesmo ao invés da 
diferença. Traçando-se agora um paralelo bastante simplificado com as reações paranóides, não necessariamente esquizofrênicas, mas persecutórias, que se vêem na contemporaneidade, é possível tentar ligá-las às multiplicidades que compõem a realidade e pensá-las em termos de implicação com um ou outro destes pólos.

Para entender essas reações persecutórias, cabe superar essa visão determinista e considerar a conexão dessas reações com a realidade na qual o sujeito vive e com a qual suasubjetividade se conecta na forma de atração ou repulsão ao corpo sem órgãos:. (..)“um rizoma não cessaria de conectar cadeias semióticas, organizações de poder, ocorrências que remetem às artes, às ciências, às lutas sociais" (Deleuze \& Guattari, 1996, p. 150). Partindo-se desse entendimento mais rizomático, será possível compreender a amplitude e a pluralidade que envolve um fenômeno paranóico de natureza persecutória, antes reduzido a um sintoma remetido à interioridade psíquica.

Uma pessoa que passa a maior parte do seu dia debaixo da cama temendo ser atingida por um tiro será paranóica? Caso ela more no subúrbio de uma grande cidade onde a violência é o principal problema da comunidade, é aceitável esse tipo de comportamento. No entanto, este mesmo comportamento pode ser apresentado por uma senhora que more em um bairro mais privilegiado desta mesma metrópole. Um dado interessante desta distinta senhora é que sua televisão fica ligada quase 12 horas por dia em canais de noticiário policial, a grande maioria sensacionalista. Será suficiente entender a patologia dessa senhora considerando apenas seu psiquismo? Ou é válido lançar um olhar mais capilar sobre os diferentes aspectos de sua realidade, que neste contexto pósmoderno é atravessada pelas demais realidades que animam o mundo? Concluindo esse paralelo, basta insistir que os diversos dispositivos mencionados se implicam com a antiprodução, com a paralisação, com a conservação, que exprimem a repulsão ao corpo sem órgãos e à sua qualidade de engendrar mudanças e devires.

A partir das miríades de conexões do rizoma, trazse à baila o princípio de multiplicidade que derruba a noção de unidade (por exemplo, a unidade do Eu), ao conceber que o rizoma se conecta a múltiplos elementos e se mantém num fluxo constante. Segundo Deleuze e Guattari (2002, p. 34), a multiplicidade se conecta de maneira simbiótica, o que pressupõe uma transformação quanto à mudança de natureza. Ou seja, quando dois ou mais elementos se conectam, eles não apenas se complementam, eles constituem um novo elemento, com uma nova forma e uma nova intensidade, prontos a se modificarem novamente. Deleuze e Guattari (1996, p. 16) afirmam: "Uma multiplicidade não tem nem sujeito nem objeto, mas somente determinações, grandezas, dimensões que não podem crescer sem que mude de natureza". A multiplicidade se define "pelo número de suas dimensões; ela não se divide, não perde nem ganha dimensão alguma sem mudar de natureza" (Deleuze \& Guattari, 2002, p. 33). Remete, pois, a pensar os fenômenos como sistemas abertos que se comunicam com outros sistemas abertos, sendo a vida uma forma de efetuação desses sistemas.

É neste aspecto de mudança de natureza que o conceito de multiplicidade entra num fluxo constante e acaba convergindo com o conceito de devir, através do qual cada indivíduo - que na perspectiva das multiplicidades, já é muitos! - pode assumir diferentes formas. "Cada multiplicidade é simbiótica e reúne em seu devir animais, vegetais, microorganismos, partículas loucas, toda uma galáxia" (Deleuze \& Guattari, 2002, p. 34). Num setting terapêutico, uma criança brinca com sua caixa de brinquedos, o analista entra num devir-criança e se conecta com a "fantasia" da mesma criança, o que lhe possibilita transitar melhor pelo universo existencial infantil. Mas é preciso cuidados para evitar mal-entendidos: o devir do qual falamos corresponde sempre a um devir minoritário, comprometido com as forças moleculares de criação. Não se trata de uma atividade imaginativa ou fabulativa, mas, ao contrário, de "encontrar a zona de vizinhança, de indiscernibilidade ou de indiferenciação tal que não seja mais possível distinguir uma mulher, de um animal ou de uma molécula." (Deleuze, 1997, p. 11) É assim que, neste devir-criança, o terapeuta se desdobra em outros devires e se transforma em carro de corrida, em soldado, em bailarina, em herói, em bruxa, em avião, em filho, em pai, etc. É entrando neste devir - ou seja, fazendo aliança com outros fluxos humanos e inumanos que se derramam pela sala - que ele se conecta com a multiplicidade de elementos que fazem parte do mundo infantil.

Sobre esta questão, ainda mais um argumento amparado em outra fonte: Em oposição à tradição racionalista, cartesiana e objetivista na qual ainda nos encontramos, Varela (2003) propõe uma visão emergente que realiza uma inversão epistêmica e paradigmática. Segundo ele, "bem no centro dessa visão emergente está a crença de que as próprias unidades do conhecimento são fundamentalmente concretas, corporificadas, incorporadas, vividas." (Varela, 2003, p. 72) Embora o argumento seja 
aplicado a uma concepção emergente nas ciências cognitivas, ele ajuda também a entender tanto a noção de devir como a da construção do conhecimento esboçadas pela esquizoanálise. Ao entrar num devircriança e experimentar outra forma de entendimento, o terapeuta não está mergulhado na interioridade do reino das abstrações, mas, mais do que nunca, está implicado com o mundo em sua dimensão processual e maquínica. Por isso, o devir que o arrasta não pode ser uma ilusão, uma fantasia, uma fabulação, mas esse reencontro singular e único com a concretude das forças que compõem o próprio Cosmo.

A fim de garantir a mutabilidade das multiplicidades, Deleuze e Guattari (1996) defendem a idéia de que estas possuem um plano de consistência que se configura como sendo a borda da multiplicidade. Ou seja, o plano de consistência é a grade, o que envolve as multiplicidades e possibilita que elas continuem se ligando e religando entre si através de linhas de fuga ou de desterritorializações ${ }^{2}$ segundo as quais elas mudam de natureza ao se conectarem (Deleuze \& Guattari, 1996, p. 17). Vale ressaltar que essa grade não é um espaço delimitado e contínuo, ela é perpassada por fissuras descompassadas. Esta descontinuidade do plano de consistência possibilita que, através do traçamento de linhas de fuga e de desterritorializações, os fenômenos agenciem fluxos que entram em sua constituição e funcionamento. Desse modo, o plano de consistência preserva a unidade da multiplicidade ao mesmo tempo em que garante sua conexão com outros elementos e entre si, reservando a ela um funcionamento autopoiético ${ }^{3}$.

Não obstante, sob influência de dispositivos de controle, o plano de consistência das multiplicidades vê a atividade das linhas de fuga e da desterritorialização se estratificar, organizar e territorializar, ou então se perder no "buraco negro" da esquizofrenia clínica. É nesse ponto que entra em questão o princípio de ruptura a-significante. Considerando-se que a palavra significante advém da palavra signo e que esta, por sua vez, possui um valor

2 Para Guattari e Deleuze, linhas de fuga e desterritorialização são meios de estabelecer relações de alteridade, de heterogeneidade, de devir outro. Enfim, são dispositivos para se conectar com multiplicidades diversas.

3 A teoria de autopoiese, desenvolvida por Maturana e Varela, concebe os sistemas vivos e a própria realidade como sistemas organizados e auto-suficientes. O eixo dessa teoria é a ciclicidade através da qual um sistema produz e recicla seus próprios componentes. e um sentido já instituído ${ }^{4}$, o a-significante pode ser entendido como o novo, como sendo uma intensidade que suga para fora, aspira e transforma o velho conceito, valor, sentido, etc. $\mathrm{O}$ a-significante abrange ainda os componentes que sustentam os signos e que auxiliam na composição de um sentido, ou seja, o papel sob o qual está escrita uma mensagem, a caneta que a escreveu, a própria tinta desta caneta, as marcas de mordida na superfície plástica desse objeto, etc. $\mathrm{O}$ princípio do a-significante se configura como uma potência de ruptura com o já instituído, visto que precede o significado em si. Desse modo, este princípio ajuda a manter viva a conectividade desterritorializante da multiplicidade, já que possibilita a conexão com o novo, com o criativo, com o nãoinstituído.

A última, mas não menos importante característica do rizoma diz respeito ao princípio de cartografia em contraponto com a noção de decalcamento. A maneira mais apropriada de entender, de maneira rizomática, as conexões que envolvem os fenômenos é através de mapas. "O mapa é aberto, é conectável em todas as suas dimensões, desmontável, reversível, suscetível de receber modificações constantemente" (Deleuze \& Guattari, 1996 , p. 22). O mapa, assim como o rizoma, possui múltiplas entradas e saídas; ele facilita cartografar o fluxo de ligações e de linhas de fuga que o princípio de multiplicidade possibilita ao rizoma efetuar. $\mathrm{Ou}$ seja, o mapa não consegue totalizar, ele dispõe de fronteiras a partir das quais se pode começar um novo mapa; e sobre um mesmo espaço, ele pode realçar outras linhas, outras trajetórias, outras combinações. Já o decalque se apresenta como uma fotografia, estática e presa à suas bordas, incapaz de registrar a riqueza e a metamorfose do rizoma. Quando se visualiza um fenômeno através do decalque, fotografase uma situação, e as possibilidades de entendimento dessa situação se restringem às bordas que a circunscrevem.

Ao observar um aluno que apresenta dificuldades de aprendizagem em sala de aula, na tentativa de melhor compreender essa dificuldade, um olhar rizomático considera aspectos familiares, arquitetônicos, institucionais, ambientais, emocionais, intra e extrapessoais... No entanto, não basta lançar um olhar; convém ao psicólogo escolar ou

\footnotetext{
Baremblitt (1998a) faz uma diferenciação entre instituído e instituinte, sendo o primeiro resultado da atividade do segundo. "O instituinte transmite uma característica dinâmica; o instituído transmite uma característica estática, congelada." O instituinte produz, enquanto o instituído reproduz.
} 
institucional se relacionar de maneira diferente com a queixa apresentada: mergulhando num devir-aluno, tomado este conceito aqui no sentido das forças moleculares potencialmente criativas que são constrangidas pelos vários dispositivos de controle institucionais. Cartografando os fatos dessa maneira, o psicólogo não só visualizará a queixa e os problemas, mas poderá se conectar com as linhas de fuga que a criança poderia efetuar em seu devir-aluno, entendido como modo de contornar e romper com os estigmas limitadores de codificação e classificação institucional. Desse modo, o próprio fracasso escolar poderá ser ressignificado como expressão das forças opressivas dos modelos tradicionais de aprendizagem. Para entender assim, o psicólogo terá que ultrapassar os limites de sua especialidade para fazer falar todas essas dimensões que se fazem presentes.

\section{SUBJETIVIDADE E RIZOMA}

Para a esquizoanálise, a subjetividade é entendida considerando-se todas as características já descritas do rizoma. Sendo assim, a subjetividade se autoconstitui e auto-reconstitui por fluxos de agenciamentos coletivos de enunciação ${ }^{5}$ com os quais ela está constantemente se conectando e reconectando. Essa concepção atribui à subjetividade uma mutabilidade que abre espaço à criação, ao novo e a novos desdobramentos. Desprende-a de estruturas cristalizadas que impossibilitam o avanço, que insistem em evocar fantasmas e manter a subjetividade sob o jugo de normas e padrões tendentes à reprodução. Tomando emprestada a idéia de Heráclito de que ninguém mergulha duas vezes no mesmo rio, porque tanto a pessoa quanto o rio já não são mais os mesmos, pode-se ilustrar a mutabilidade da subjetividade, pois a cada passo ou a cada mergulho o indivíduo se conecta com múltiplos equipamentos de subjetivação e se metamorfoseia durante este percurso.

Para Rolnik (1997), a tessitura que envolve a subjetividade e produz a configuração interiorexterior, traça constantes dobras e, a cada dobra, forma diferentes diagramas. Deste modo, é possível pensar cada modo de existência como uma dobra da pele que delineia o perfil de uma determinada figura da subjetividade.

Segundo Guattari (2000, p. 162), agenciamentos coletivos de enunciação implicam multiplicidades humanas, devires animais, vegetais, maquínicos, incorporais, infrapessoais, etc. $\mathrm{O}$ agenciamento propriamente dito, diz respeito ao crescimento das dimensões da multiplicidade à medida que ela aumenta suas conexões.
Vale esclarecer que a idéia de dobra é utilizada para demonstrar que o "interno" é apenas um caso particular do "externo", mas que se faz dele. Dessa forma o dentro e o fora caminham lado a lado, interpenetrando-se continuamente, constituindo incessantemente novas existências ou novas figuras da subjetividade. Assim, a subjetividade se configura e reconfigura num processo inseparável do fora que nutre e sustenta a realidade.

Sendo assim, a subjetividade se faz, ela está num devir-subjetividade. Mas o que faz com que a subjetividade se mantenha nesse devir, nesse movimento de ligação e religação? Pode-se dizer que o desejo é a força motriz dessa máquina subjetiva, é o desejo que impulsiona o ser humano a produzir, a imergir num devir criador e se conectar com diferentes máquinas processuais. É o desejo que encontra, em meio às forças caóticas da multiplicidade dos universos de referência, a força da criação, do novo e do diferente. $\mathrm{Na}$ concepção esquizoanalítica, o desejo é:

(...) imanentemente produtivo, gera e é gerado no processo mesmo de invenção, metamorfose ou "criação" do novo. Sua essência não é exclusivamente psíquica, pois participa de todo o real(...) Assim entendido, o desejo também está parcialmente submetido a entidades repressivas, mas estas não são exclusivamente psíquicas, e sim um complexo conjunto ao mesmo tempo político, econômico, comunicacional, etc. (Baremblitt, 1998a, p. 144).

A palavra desejo remete nosso pensamento ao conceito de inconsciente. Na concepção psicanalítica o inconsciente é entendido como sendo um depósito de conteúdos reprimidos pela censura, remetendo-o, pois, a uma interioridade psíquica nivelada pela psicodinâmica de cada indivíduo.

Guattari e Deleuze mostraram que o dito inconsciente não se limita a um reservatório de desejos incestuosos ou agressivos recalcados, mas que está aberto sobre a História, a sociedade e o cosmo. O inconsciente total, que não é mais concebido como uma entidade intrapsíquica, são os agenciamentos coletivos de enunciação, os rizomas heterogêneos ao longo dos quais circulam nossos desejos e pelos quais se lançam e se relançam nossas existências (Levy, 2004).

Desse modo, para a esquizoanálise, o inconsciente é marcado pelas multiplicidades, é perpassado por 
raças, costumes, tecnologias, momentos, imagens, culturas, crenças, religiões, pelo econômico, político, social, etc. Ele se configura como uma grande máquina desejante, uma usina de forças que obtém energia, ao mesmo tempo em que imprime suas forças, por trocas com elementos intra e extrapsíquicos. Desse modo, o inconsciente

(..) superpõe múltiplos estratos de subjetivação, estratos heterogêneos, de extensão e de consistência maiores ou menores. Inconsciente, então, mais "esquizo", liberado dos grilhões familialistas, mais voltado para práxis atuais do que para fixações e regressões em relação ao passado. Inconsciente de Fluxo e de máquinas abstratas, mais do que inconsciente de estrutura e de linguagem (Guattari, 2000, p. 22).

Dessa forma, entende-se que o inconsciente é posto a se mover por uma força desejante que o coloca em constante movimento e mutação; ele se constitui e reconstitui por dobras, desdobras e redobras. Partindose dessa concepção desejante de inconsciente, para a esquizoanálise "a questão não é nunca reduzir o inconsciente, interpretá-lo ou fazê-lo significar segundo uma árvore. A questão é 'produzir inconsciente' e, com ele, novos enunciados, outros desejos: o rizoma é esta produção de inconsciente mesmo"(Deleuze \& Guattari, 1996, p. 28).

Desse modo se configura uma subjetividade pulsátil que desenha e redesenha um diagrama de conexões que continuamente faz maquinações externas e internas No entanto, este devir subjetivo pode ser atravessado ${ }^{6}$ por fluxos estratificantes e territorializantes que acabam desembocando em subjetividades engessadas. Guattari (1993) classifica esses fluxos ${ }^{7}$ como vozes de poder, de saber e de autoreferência que atuam no processo de subjetivação por intermédio dos equipamentos coletivos de subjetivação. O funcionamento desses equipamentos envolve "máquinas de expressão que podem ser tanto de natureza extrapessoal, extra-individual, (...), quanto de natureza infra-humana, infrapsíquica, infrapessoal (...)" (Deleuze \& Guattari, 1999, p. 31). Pode-se dizer que a subjetividade se engendra a partir de máquinas de expressão sociais, políticas, poéticas, estéticas,

6 Baremblitt (1998a) afirma que a rede social é constituída pela atuação conjunta de instituídos-instituinte e organizados-organizantes. À atuação conjunta a nível da função, do conservador e do reprodutivo, dá-se o nome de atravessamento.

7 Segundo Guattari (1993), essa classificação não diz respeito a uma fundação estrutural universal, trata-se de instrumentos de uma cartografia especulativa. afetivas... Assim, consideram-se esses equipamentos de subjetivação como um dos elos de ligação entre a realidade e a vida psíquica. É em meio a este movimento de engendramento que as vozes de poder, de saber e de auto-referência entram em ação.

No que se refere às vozes de poder, pode-se dizer que estas "circunscrevem-se e cercam de fora os conjuntos humanos, estabelecendo relações de poder territorializado à medida em que estas desenvolvemse pautadas na atribuição de poder a algo ou alguém" (Parpinelli, Stocker e Souza, 2003, p. 2). Dessa forma, as vozes de poder carregam consigo uma vocação para a dominação e o controle. De acordo com Foucault (1995), o principal objetivo de quem exerce o poder sobre alguém é interferir no comportamento e ação do outro. Sendo assim, tanto Foucault (1995) quanto Guattari (1993) caracterizam as relações de poder como processos de sujeição impostos por quem o exerce, com o objetivo de fazer com que o outro aja, pense, sinta e se posicione de acordo com os interesses de quem detém o poder.

A realidade oferece uma gama de exemplos acerca da atuação dessas vozes. O sistema que baliza o funcionamento da maioria das instituições, pelo menos das mais convencionais, é de natureza hierárquica. Mesmo quando não há uma pessoa no topo da pirâmide institucional incumbida de mandar em seus subordinados a fim de manter o bom funcionamento da instituição, a própria composição da instituição, sua dinâmica, suas ligações, aberturas e fechamentos transbordam relações de poder. É muito comum encontrar nos meios de comunicação impressa, assim como na fala de muitos de seus leitores, frases construídas utilizando comandos diretos, com verbos no imperativo, que transfiguram ordenações quanto a modos de agir, de pensar e até mesmo sentir. A própria arquitetura da sala de aula, a disposição das carteiras dos alunos e a localização destas em relação à mesa do professor são elementos que podem ser entendidos como expressões das vozes de poder, já que corroboram o distanciamento hierárquico comumente mantido entre professor e aluno: ao primeiro cabe passar o conteúdo da matéria e ao segundo absorver complacentemente tudo que este último disser.

Quanto às vozes de saber, Guattari (1993, p. 179) as descreve como aquelas "que se articulam de dentro da subjetividade às pragmáticas técnico-científicas e econômicas". É a partir dessa articulação que se pode perceber um grau de comprometimento entre a constituição de subjetividades e os valores próprios de cada momento histórico. Ou seja, as vozes de saber 
não seriam todo o conhecimento produzido num dado período, mas sim, aquele conhecimento produzido que entre em convergência com os interesses dominantes de cada época. Assim, essas vozes seriam o saber predominante de cada momento histórico, o qual, ao predominar, confina, hegemoniza, direciona e circunscreve o conhecimento das massas humanas.

Um dos aspectos deste momento histórico, quanto ao conhecimento, é a fragmentação do saber, que contribui para o surgimento de tantas especialidades. Por mais paradoxal que pareça, a fragmentação do saber, que, em tese, abriria as fronteiras do conhecimento e possibilitaria a busca e o acesso a novos saberes, atua como um dispositivo de desapropriação. A criação de tantas especialidades denota a fragmentação e a invalidação do conhecimento de que os coletivos humanos dispõem, tornando-os sujeitos àquiles que Baremblitt (1998a) denomina experts ${ }^{8}$. Ocorre a desterritorialização do saber popular para reterritorializá-lo a partir da competência de um saber hegemônico. Tendo-se em vista que a fragmentação do saber se configura como a criação de novos pólos de poder aos quais os grupos humanos se submetem, pode-se dizer que esta tende a refrear o processo de emancipação humana.

Pode-se perceber a atuação das vozes de saber em grande parte dos livros didáticos utilizados no ensino fundamental, médio e superior. Na maioria dos livros infantis as empregadas domésticas são negras, as mulheres são donas de casa, os executivos são homens brancos e os operários são negros, a família é constituída de pai, mãe e filhos, etc. Percebe-se em suas histórias e ilustrações uma série de valores morais, sociais, estéticos e de conduta imbricados com a lógica dominante. Ou seja, esses livros são equipamentos coletivos de subjetivação através dos quais saberes pasteurizados e serializados são veiculados visando tornar hegemônicos coletivos existenciais.

Considerando-se a relação coercitiva e comprometida dessas vozes, pode-se dizer que elas atuam de forma a interromper as linhas de fuga da subjetividade e acabam cercando-a com normas, padrões e valores que impossibilitam a criação do novo. Ou seja, essas vozes interrompem o fluxo desejante do devir subjetivo e o aprisionam dentro das grades da reprodução.

8 Baremblitt (1998a) define os experts como sendo aquelas pessoas detentoras do saber, podendo o termo ser entendido como sinônimo de especialista.
No entanto, há um grupo de vozes que resgatam o caráter criador da subjetividade e impedem que esta se constitua como subjetividade sujeitada. São as vozes de auto-referência, definidas por Guattari (1993, p. 179) como forças "que desenvolvem uma subjetividade processual, autofundadora de suas próprias coordenadas, autoconsistencial." O termo processual se refere aos múltiplos fatores que não cessam de perpassar a subjetividade, entre os quais estão as vozes de saber e de poder, tendentes, como já foi elucidado, a produzir subjetividades reprodutoras e cristalizadas aos padrões e normas da sociedade vigente.

Desse modo, cabe às vozes de auto-referência atuar como um filtro e decodificar as informações advindas do entrelaçamento das vozes de poder e de saber. Essa decodificação pode ocorrer em dois sentidos: pode desembocar num processo de singularização, onde o sujeito se conecta com máquinas de criação e entra num movimento de ruptura com o instituído, criando novas formas de ser e de se perceber no mundo; ou pode entrar num processo de individuação, onde o indivíduo reproduz e aceita os conteúdos propagados pelos diferentes vetores de dominação que participam do processo de subjetivação. Dessa forma, as vozes de auto-referência seriam um instrumento que possibilita aos conjuntos humanos atuar de maneira criadora na realidade, ou seja, atuar como elementos ativos no virtual ${ }^{9}$, num devir realidade.

\begin{abstract}
O modo pelo qual os indivíduos vivem essa subjetividade oscila entre dois extremos: uma relação de alienação e opressão, na qual o indivíduo se submete à subjetividade tal como a recebe, ou uma relação de expressão e criação, na qual o indivíduo se reapropria dos componentes da subjetividade (Deleuze \& Guattari, 1999, p. 33).
\end{abstract}

Feita toda essa discussão acerca da maneira como o esquizoanálise concebe a subjetividade, paira no ar um questionamento: essa concepção pode oferecer outra inteligibilidade para aqueles fenômenos colocados sob a alçada exclusiva da psicologia e produzir desdobramentos práticos hoje?

$\mathrm{Na}$ medida em que existe a possibilidade de reapropriação do sentido, os grupos humanos não se encontram fadados a reproduzir. Subjetividades autoconsistenciais e processuais podem ser produzidas, há meios para se conceber uma

9 Para Deleuze, o virtual é um devir, é a realidade ainda não consumada. 
subjetividade que se metamorfoseia a cada conexão, que não se encontra confinada num espaço predeterminado por poderes, saberes, normas e padrões. Desse modo, caberia ao profissional de Psicologia, nas diversas áreas de intervenção, potencializar nos grupos humanos essa reapropriação dos componentes da subjetividade e acionar a capacidade de discernimento das vozes de autoreferência.

Para isso, o próprio profissional deveria rever alguns conceitos e modificar sua prática, a fim de evitar intervenções que tendem a reduzir a complexidade dos fenômenos a determinismos teóricos. Ou seja, cabe ao psicólogo entrar num movimento através do qual ele possa se desprender dos padrões sociais vigentes, para não mergulhar no fluxo coercitivo das vozes de saber e poder. Abrir-se-ia então um novo entender e agir na realidade de maneira rizomática, imergindo num devirdesejante de mudanças e de criações, atuando no seu diaa-dia como um agente que propicie a multiplicação de linhas de fuga.

Não obstante, é preciso que se ressalte aqui, mais uma vez, que o "olhar" esquizoanalítico não corresponde tão-somente a um aporte teórico para renovar as interpretações e as práticas psicológicas, mas, ao contrário, abrange uma complexa concepção de mundo, aqui incluídos os diferentes níveis de realidade que o constituem, inclusive as dimensões humanas inseparáveis do próprio mundo. Com isso, pretende-se destacar as contribuições que a esquizoanálise tem oferecido em inúmeros campos, além do "psi”, fornecendo novo fôlego para movimentos minoritários revolucionários, produções artísticas "menores", além de todo tipo de esforços criativos transversais que buscam apreender não mais o "objeto linear", mas os fenômenos complexos que ultrapassam os limites do "dado" e vibram, afetam, dinamizam a vida, na forma de intensidades.

\section{REFERÊNCIAS}

Baremblitt, G. (1998a). Compêndio de Análise Institucional e outras correntes. Rio de Janeiro: Record.
Baremblitt, G. (1998b). Introdução à Esquizoanálise. Belo Horizonte: Cultura Ltda.

Deleuze, G. (1997). Crítica e Clínica. São Paulo: Editora 34.

Deleuze, G. \& Guattari, F. (1976). O anti-edipo: capitalismo e esquizofrenia. Rio de Janeiro: Imago.

Deleuze, G. \& Guattari, F. (1996). Mil Platôs: vol 1. São Paulo: Editora 34.

Deleuze, G. \& Guattari, F. (1999). Mil Platôs: vol 3. São Paulo: Editora 34.

Deleuze, G. \& Guattari, F. (2002). Mil Platôs: vol 4. São Paulo: Editora 34.

Dostoievski, F. (1988). Noites Brancas. São Paulo: América do Sul.

Foucault, M. (1995). O sujeito e o poder. Em H. Dreyfus \& P. Rabinow, Michel Foucault: uma Trajetória Filosófica (pp. 231-249). Rio de Janeiro: Forense. (Trabalho original publicado em 1982)

Guattari, F. (1993). Da Produção de Subjetividade. Em A. Parente, Imagem Máquina (pp. 177-191). São Paulo: Editora 34.

Guattari, F. (2000). Caosmose: um novo paradigma estético. São Paulo: Editora 34.

Levy, P. (2004). Plissê Fractal: ou como as máquinas de Guattari podem nos ajudar a pensar o transcendental hoje. Disponível em: http://www.unir.br/ portal/plissefractal.html. (Acessado em 10/09/2004)

Lobo, L. F. (2004). Pragmática e subjetivação por uma ética impiedosa do acontecimento. Psicologia em Estudo. 9(2), 195205.

Parpinelli, R. S., Stocker, I. \& Souza, E. W. S. (2003). A atuação das vozes de saber, de poder e de auto-referência na constituição da subjetividade do ser mulher - uma visão esquizoanalítica. Em I Congresso Internacional e V Semana de Psicologia. Maringá: Anais (CD-ROM).

Rolnik, S. (1997). Saúde Loucura- subjetividade. São Paulo: Hucitec.

Varela, F. (2003). O reencantamento do concreto. São Paulo: EDUC.

Endereço para correspondência: Roberta Stubs Parpinelli, Rua João Gomes Navarro n. 61, CEP 86990-000, Marialva-Pr. E-mail: rostubs@yahoo.com.br 